title. It was jolted into life, as Wood explains, by Justice Lewis Powell in

Diversity Rules, Peter W. Wood, his eccentric findings in the Bakke Encounter Books, 2019, pp. 71, \$8.95, paperback.

On Diversity: The Eclipse of the Individual in a Global Era, Russell Jacoby, Seven Stories Press, 2020, pp. 229, \$25.95, hardbound.

\title{
The Meaning of Diversity
}

\section{Matthew Stewart}

In Diversity: The Invention of a Concept (2003), Peter Wood made a brilliant typographical move with his key term. It is a move that I will be using in this piece. He reserved Roman font diversity to indicate what everyone had long understood by that word: variety and difference, including, centrally, that found among human beings and between different cultures. Italicized diversity, however, was used to indicate the new politicized concept referred to in the multicultural movement that flowered in the 1980s. By 2003 diversity was already institutionally rooted and well on its way to becoming not just a concept, but an actively expressed ideology. It has since become a regime. ${ }^{1}$

Wood's new book, Diversity Rules, serves both as a read-in-one-sitting primer on diversity and an update of his first volume. Diversity's progress through the institutions has continued apace, deepening roots and spreading branches, while its progress through popular and commercial culture has accelerated. In short, the update is a story of more and deeper. The update also includes analysis of key court cases subsequent to Invention of a Concept, including Grutter $v$. Bollinger (2003) and Fisher $v$. the University of Texas (2013, 2016).

This is a book to hand to anyoneincluding young adults-who wonders just how we got where we are. For example, those on the academic

1 In the first three pages of his book, Russell Jacoby refers to diversity as an "idea," a "rhetoric," a "jargon," a "cult," an "enterprise," an "industry," and a "demand." Those in higher education will appreciate his later description of it as the era's "ambient noise" $(1-3,177)$. 
job market may be baffled by a job application's mandate to produce a statement explaining "how you have already promoted and how you will continue to promote diversity and inclusion in your teaching, research and professional duties." Job candidates might well sense that the response to this statement rather than their training or disciplinary accomplishments will be the decisive factor in their chances of being hired. For such as these, Diversity Rules will explain how it came to be that espousing a political creed is necessary to obtain a faculty position. Many readers coming to Wood for the first time in Diversity Rules will surely seek the first volume's more expansive analyses, given the characteristic wit, arresting turns of phrase and illuminating metaphors that enliven the pages of this newer volume.

Missing from the newer volume are the extensive explorations of Roman-font diversity available in the first book, such as those in the chapter "Diversity before Diversity." Here the admirable, even delightful, aspects of old-style interest in diversity are keenly remembered without romanticizing them. Wood surveys wide swathes of American reading: travel literature, geography books and early ethnographies, and finds that American interest in other cultures ran deep until about 1930, when the present era of non-judgmentalism began to take root, only to produce and increasingly shallower conception of culture. The nation eventually arrived at the twenty-first-century's "brittle new creed of diversity." (81) Shallow and brittle: one thinks of the insistent celebration of multiculturalism on university campuses, while those same institutions have largely judged foreign language requirements to be unnecessary impediments to student desires.

In The Invention of a Concept, Wood pinpointed 1988 as the annus mirabilis of diversity, the year it moved into the house. (242) At first diversity was allowed to live with us as a special guest whose manners were different from ours; we looked the other way and bit our tongues out of politeness at his high-handedness; then he moved in permanently, quickly rearranged the furniture and sent out for new fixtures, while setting us to dusting and shining. What has happened in the two decades (roughly) since Wood's first book? The emphasis on group identity has grown to seem natural in academia. A cohort of students now enters the classroom already having absorbed the preachments of diversity via pre-K-12 education and through every aspect of popular culture. The companies that hire 
them after graduation will in turn have their own diversity statements, diversity officers, diversity hiring and promotion initiatives, and diversity training workshops. Details may vary, but the ethos is ubiquitous. Pushback or open questioning, once impatiently accommodated, have now become anathema. ${ }^{2}$ Wood concludes that, "We are ... in a world where diversity is a social norm, not a frontier." (39)

Indeed, with the aid of social media, group identity has been weaponized, as "identity politics coalesces around group grievance." (54) Diversity's tag-along little brother inclusion has by now grown up big and strong. "Inclusion," Wood writes, "is a demand that the prevailing standards, whatever they were, must make way for the cultural preferences of the newly arrived.” (37) Thus tampon machines appear in every male washroom on a large university campus with nary a question asked. A waste of money, that. Thus do an increasing number of activists assert that "linear thinking" and evidencebased argument are Trojan horses for maintaining white supremacy and that alternate standards of scholarship must be introduced. ${ }^{3}$ A waste of the Enlightenment, that.

What else has happened? Diversity has fathered Social Justice, which strides-sometimes on stiltsthrough campuses, corporations, and governmental bodies. Open activism is now fully at home in the modern university. Political intrusions into scholarship and teaching that once would have been forbidden, then discouraged, then tolerated with a blind eye are now sponsored by the university, often lavishly. Exhibit One: the town hall meetings, roundtables, special symposia, and the newest series of diversity initiatives widely announced during the spring semester of 2020 in conjunction with \#BlackLivesMatter and the widespread protest movement. ${ }^{4}$ More and deeper.

As Wood makes clear in both volumes, the intended end point of Affirmative Action and the language used on its behalf was integrationist. Because it is a movement that insists

2 If one lays low, very low, indifference to diversity might go undetected, but "to criticize diversity," Jacoby writes, "is to invite ostracism; you might as well climb on a desk and yell, 'I am a racist'." Diversity's "relentless celebration ... overwhelms any skeptics." $(1,9)$

3 See for example, James Lindsay, "Decolonizing the Curriculum," Academic Questions 33, no. 3 (Fall 2020), 448-54.

4 Exhibit 2: the various open letters and public pronouncements issued by universities and professional organizations. For an eloquent public demurrer from this rush to selective activism, see Glenn Loury's letter to Brown University published in City Journal, https://www.city-journal.org/brown-university-letter-racism. One is reminded that during the 1990 s political correctness wars, this journal also published the famous black critic Stanley Crouch's devastating takedown of Afrocentrism, https://www.city-journal.org/html/afrocentric-hustle-12584.html. 
upon group loyalties and group rights, diversity's growing demands have come to sound increasingly separatist. Older American core values, namely liberty and equality, have been attenuated. For those under thirty, they are often poorly understood and have been replaced by inclusion and equity, power-play words cagily deployed with shifting meanings. Actual diversity-that is real individual differences-are of no interest to identitarians. This central point is rued by both Wood and by Russell Jacoby.

Jacoby's new book provides social and intellectual history as lamentation. If true diversity has not disappeared altogether, Jacoby assures us that it has dwindled, the word that he most commonly uses to describe its attenuation. Like Wood, Jacoby finds the contemporary conception of diversity to be thin stuff, born in the university, the substance of "graduate seminars where professors serve gluten-free gibberish to aspiring professors," (26). Joining Wood in lamenting the centrality of groups to the formulations of diversity, Jacoby places a particular emphasis on commercial culture and globalization as homogenizing forces. True diversity is defined by individuals, who, ideally, are capable of showing the same variety as the glorious variety evident in nature. But commercialized mass culture has pushed a much greater sameness onto people. At deeper levels we are more homogenous than ever. Do my Nikes, a little bit different in style and color than your Adidas, define my individuality? How about our Facebook pages? Does the fact that we have jumped on board the Diversity Train instantiate our individuality? Not likely, says Jacoby. It seems in fact much more likely to point towards a conformist mindset.

While the book begins and ends with chapters colored by skillful polemics, Jacoby's primary goal is to differentiate the diversity of contemporary ideologues and bureaucrats from deeper, more substantial instances of human variety that make true individuality possible. While he lands a number of deserved blows on the campus left, he is not writing to promote a conservative agenda, but as a social and intellectual historian interested in the conception of diversity from the early modern period unto the present. Left diversophiles often come off here as superficial and opportunistic. The right gets away more lightly, but is chided for its over-reliance on the market, which in a consumeroriented, globalized culture acts as a homogenizing force. The author 
of numerous well-reviewed books, and by no means an establishment conservative (his books have been praised and blurbed by prominent figures on the left), Jacoby reports elsewhere that he had great difficulty getting the present volume published. Merely to ask questions about diversity is apparently going much too far for university presses. ${ }^{5}$

Jacoby asks us to consider two possible examples of real diversity in contrast to diversity. On the one hand, there is the commonplace case of Group $\mathrm{X}$ asking for greater inclusion in Activity Y. Let us suppose, for instance, that Asian Americans are pressuring for more TV and film roles. On the other hand, there is the case of the Amish or Hasidic Jews, who ask for no such thing, and would run from greater inclusion if it were offered. The first instance involves an active demand that someone else do something on behalf of group $\mathrm{X}$; the second instance involves a passive, leave-us-alone demand. The first instance would be instantly recognized by diversophiles as diversity in action; the second instance would never occur to them, and, most likely the particular groups in question would strike the progressive mind as more than a little offputting. (March for the rights of the Mennonites! Not likely.) Most directly to Jacoby's point, the first instance is actually a call for admission, a demand to be treated with a fair opportunity to participate in the general culture. The desire is justified, writes Jacoby, "but only in the loosest sense does this [demand] entail more diversity.” (6) In the first instance, "identities devolve into labels and styles that are employed to open doors." (7) The truly diverse Amish and Hasids would keep the doors shut and hope their children don't note their location. This counterexample provides an effective illustration, but even here, one notes, diversity remains attached to groups.

In an effort to trace the dwindling of diversity, Jacoby analyzes clothing, which he sees as becoming increasingly uniform, and, at greater length, he explores the loss of linguistic variety, including the phenomenon of language extinction. These cultural trends find a parallel in the worlds of biology and ecology, where species loss, monoculturalism, and biotic homogenization are a cause for concern. Those noting such losses (“diversity doomsters”) might seem more realistic than the more

5 Jacoby concludes that his "argument rains on a very large parade and nowadays the professoriate does not like to get wet. To criticism it responds with avoidance at best, censorship at worst." Thus eight university presses turned him down, before he tried a different sort of publisher, https://heterodoxacademy.org/blog/publishing-on-diversity/. 


\section{numerous "diversity celebrants,"} but Jacoby finds that the two groups share a spurious "consumer notion of diversity" which assumes that more is better. "A saccharine multiculturalism, the source of much diversity nonsense, underlies both camps," he writes, as does an emotiondriven exoticism. (49-50) Alarm over loss ought to be underpinned with a consideration of what exactly is lost, but selective nonjudgmentalism rules. If honor killings, genital mutilation and forced marriage would disappear, should that loss be lamented? Diversity doomsters and celebrants alike turn away from such questions. Why should something vulnerable automatically be seen as valuable? No one applauds the careless disappearance of a rain forest people or their language, but then again, how helpful is it to social cohesion for a given nation to house dozens or even hundreds of languages within its borders? (52) And (apologies for bringing this up again), why such emotional expenditure about the loss of small and distant languages and so little concern for the gutting of language study right here at home?

Much of the book is devoted to analyzing the various thoughts about diversity that have occupied the minds of philosophers from the Enlightenment onwards. Here one finds a list of true diversophiles, who stand in contrast to today's professionalized bandwagoners, do-gooders, commissars, and rentseekers. ${ }^{6}$ Humboldt, Montesquieu, Herder, and Constant make the list, as do lesser known figures such as Friedrich Schleiermacher and Justus Möser (the "German Burke”), about whom this reviewer was pleased to learn more. Two venerable scholars of previous generations, Jacob Burckhardt and Arthur O. Lovejoy, figure prominently as well.

Jacoby's learned summary finds its climax in John Stuart Mill and Alexis de Tocqueville, touchstones for Jacoby's conception of deeper forms of diversity. "Unlike today's diversity boosters," he writes, "Mill saw diversity not simply as choices or inherited characteristics, but as something deeper, modes of living." (146) Once Mill read Democracy in America, his concern began to shift away from fear of the state's power to encroach upon personal freedom and to fix his attention on the decrease of individuality and the growing power

6 For data on the diversity industry in academe, see Mark Pulliam, https://www.city-journal.org/campus-diversity-bureaucracies-16223.html. Christopher F. Rufo has explored the most recent intrusions into governmental agencies, a story which has been picked up on by national media as I write this review, https://www.city-journal.org/critical-race-theory-federal-training. 
of "the masses."7 Jacoby joins Mill in the belief that variety is not only of intrinsic value, but also of civic importance. Democracy is weakened by uniformity, its citizens more susceptible to group think and less capable of critical thinking.

Was there a golden age of true diversity? And are we now truly more alike one-to-another than we have ever been? While Jacoby is much too intelligent to answer the first question literally with a yes, his study nonetheless tends in that direction. This is something of a weakness insofar as he gives few examples of what constitutes the more meaningful forms of individuality once to be found, so that we may see how they differed from the more superficial contemporary forms that he criticizes. If Mill was anxiously watching the massification of society, what valuable qualities and potentialities, what "modes of living," were disappearing from the individualism whose diminution he lamented? Let us grant the people of pre-Millian England all the variety that is claimed for them. To what extent did their forms of individuality allow them to think more freely about crucial matters than we are able to think in our globalized, commercially oriented world? As to the question of present-day uniformity posed above, one wants to answer "yes and no," or at least "yes, but." The "but" here is generated by the very deep political divisions that have arisen over the past decade. While civil war talk may be overly anxious or hyperbolic, the frequently used trope of political tribes carries much weight. Members of tribes may well not think for themselves, but the thoughts of the tribes are very different one from another.

The historical explorations of both volumes are informative, but most tellingly they are fostered by a desire to rectify the present. Today's diversophiles tout a thin, restricted, tendentious and overly politicized version of diversity whose fundamental fallacy is to define individuals by the groups they belong to. If there is no going back, what is the way forward?

7 Mill wrote highly favorable reviews of both volumes of Democracy. The review of volume II is over eighty pages long. 